\title{
Correction to: Similarities and differences in tissue distribution of DLK1 and DLK2 during E16.5 mouse embryogenesis
}

\author{
P. Garcia-Gallastegi · A. Ruiz-García ${ }^{2}$ - G. Ibarretxe ${ }^{1}$ - S. Rivero-Hinojosa ${ }^{3}$ - A. D. González-Siccha ${ }^{4} \cdot$ J. Laborda $^{5}$. \\ O. Crende ${ }^{1} \cdot$ F. Unda ${ }^{1}$ (D) J. J. García-Ramírez ${ }^{2}$
}

Published online: 16 May 2019

(c) Springer-Verlag GmbH Germany, part of Springer Nature 2019

\section{Correction to: Histochemistry and Cell Biology https://doi.org/10.1007/s00418-019-01778-4}

In the original publication of the article, some symbols in Figure 3 were not correctly aligned with the image.

The corrected Fig. 3 is given below.

The original article can be found online at https://doi.org/10.1007/ s00418-019-01778-4.

F. Unda

fernando.unda@ehu.es

1 Department of Cell Biology and Histology, Faculty of Medicine and Nursing, University of the Basque Country, UPV/EHU, 48940 Leioa, Bizkaia, Spain

2 Department of Inorganic and Organic Chemistry and Biochemistry, Medical School, Regional Center for Biomedical Research, Unidad Asociada de Biomedicina (UCLM-CSIC), University of Castilla-La Mancha, Calle Almansa 14, 02008 Albacete, Spain

3 Center for Cancer and Immunology Research, Children's Research Institute, National Health System, 111 Michigan Ave NW, Washington, DC 20010, USA

4 Departamento de Bioquímica, Facultad de Farmacia y Bioquímica, Universidad Nacional de Trujillo, Av. Juan Pablo II s/n, Trujillo, Peru

5 Department of Inorganic and Organic Chemistry and Biochemistry, Pharmacy School, Regional Center for Biomedical Research, Unidad Asociada de Biomedicina (UCLM-CSIC), University of Castilla-La Mancha, Avda José María Sánchez Ibáñez s/n, 02008 Albacete, Spain 
Fig. 3 Embryonic vertebral column histology. a, b H\&E increasing magnification of intervertebral bodies (IV), vertebral bodies $(\mathrm{V})$, and nucleus pulposus (asterisk). d, e Immunohistochemistry and c in situ hybridization for DLK1 are positive in the cartilage of the intervertebral bodies and scant in the nucleus pulposus, whereas $\mathbf{g}, \mathbf{h}$ immunohistochemistry and $\mathbf{f}$ in situ hybridization for DLK2 are strongly labeled in the nucleus pulposus. Scale bars: (c, f) $100 \mu \mathrm{m},(\mathbf{a}, \mathbf{d}$, g) $50 \mu \mathrm{m}$, and (b, e, h) $20 \mu \mathrm{m}$

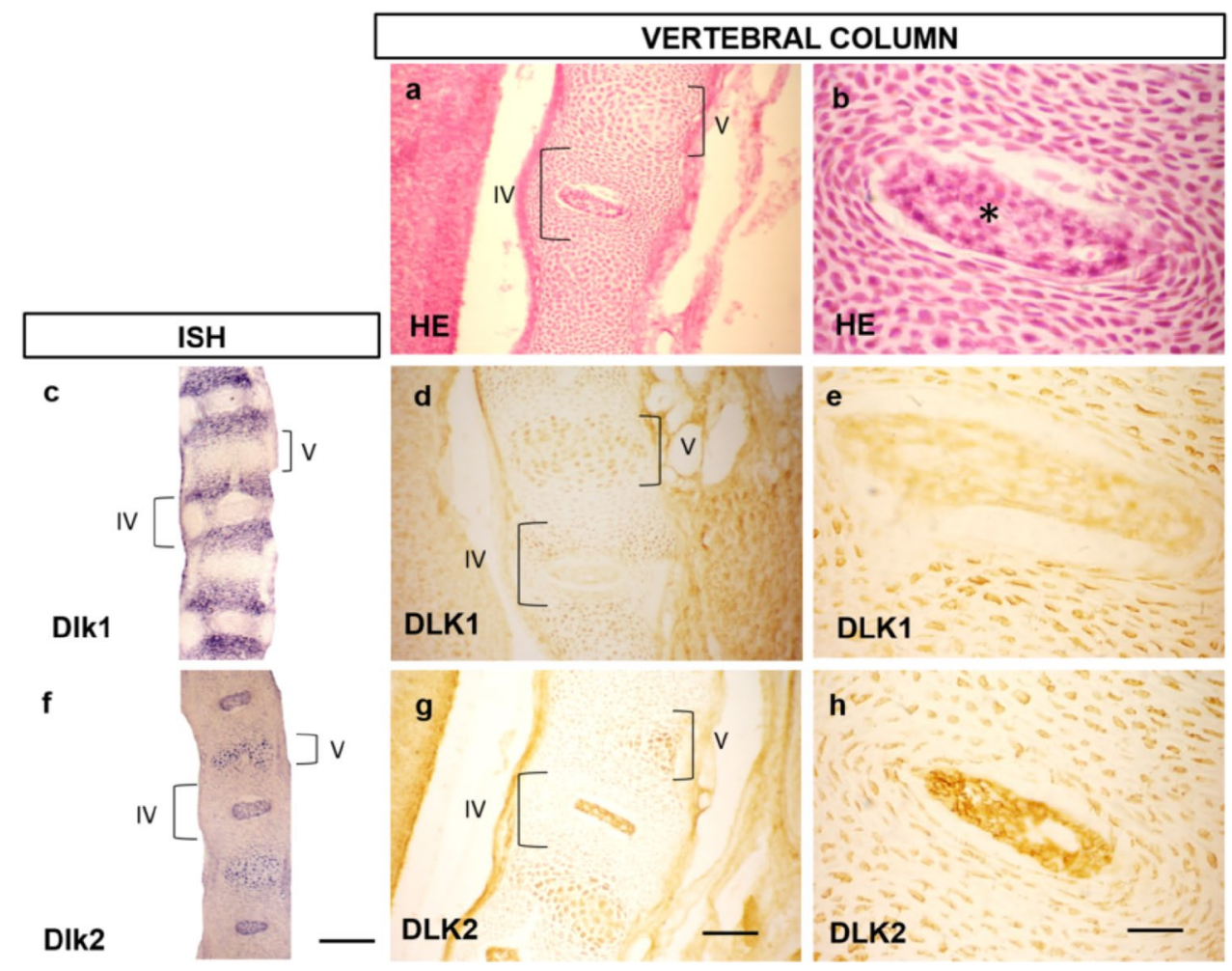

